\title{
GOLPES DE ESTADO EN EL SIGLO XXI. UN EJERCICIO COMPARADO HAITÍ (2004), HONDURAS (2009) Y PARAGUAY
} $(2012)^{(*)}$

\author{
COUPS D'ÉTAT IN THE XXITH CENTURY. HAITI (2004), HONDURAS \\ (2009) AND PARAGUAY (2012): A COMPARATIVE ANALYSIS
}

\author{
Lorena Soler ${ }^{(* *)}$ \\ Universidad de Buenos Aires, Buenos Aires (BA), Argentina
}

Resumen: El trabajo tiene como objetivo analizar las características que asumen los golpes de Estado de comienzo del siglo XXI, ejecutados contra presidentes legítimos, elegidos democráticamente. Desde la perspectiva de la sociología histórica, comparar tres experiencias: Haití (2004), Honduras (2009) y Paraguay (2012) indagando en los actores - nacionales como internacionales - como en la emergencia de nuevos mecanismos golpistas puestos en práctica en América Latina. Finalmente se arriba a una propuesta conceptual mínima de golpes del estado en el siglo XXI.

Palabras clave: Golpe de estado; Cambio político; Sociología histórica.

Abstract: The paper aims to analyze the characteristics that coups d'état $\mathrm{s}$ assumed in the first years of the XXIth Century, that were effected against presidents democratelly elected. From the perspective of historical sociology, we compare three different experiences: Haiti (2004), Honduras (2009) and Paraguay (2012). We inquire into the - national and international - actors and the emergency of new coup mechanisms that have taken place in Latin America. Finally, we arrive to a minimum conceptual proposal of coup d'état in the XXIth century.

Keywords: Coup d'état; Political change; Historical sociology.

(*) Este texto tiene su origen en una conferencia dictada en el International Studies Association, FLACSO, Buenos Aires, 23 de julio 2014. Luego ha sido reelaborado en base a la incorporación de los casos y discutido en el ámbito de una investigación colectiva que dirijo junto a Verónica Giordano Nuevas derechas y democracia en América Latina (19802010) en el marco de la programación científica de Ciencia y Técnica de la Universidad de Buenos Aires. Agradezco a los integrantes del equipo por los agudos comentarios y observaciones vertidas, sin los cuales este texto adolecería aún más.

$\left({ }^{* *}\right)$ Doctora, Investigadora CONICET con sede en el Instituto de Estudios Socales Latinoamericanos; Profesora y Coordinadora académica de la Maestría en Estudios Sociales Latinoamericanos de la Facultad de Ciencias Sociales, de la Universidad de Buenos Aires. E-mail: <lorenamarinasoler@gmail.com>. Recibido em: 24.03.2015; aceptado em: 18.06.2014. 


\section{INTRODUCCIÓN}

Todavía es una reflexión marginal al campo de las ciencias sociales el estudio de las características que asumen los Golpes de Estado en el siglo XXI. Entre otras razones, la mirada ha estado depositada en analizar el cambio social que se inicia en el siglo XXI, aunque con conceptualizaciones muy amplias que van desde nueva izquierda a gobiernos posneoliberales o antineoliberales, pasando por rupturas populistas a estudios sobre las reconfiguraciones del bloque hegemónico.

Aquí tenemos por objetivo analizar lo que ha quedado solapado en la agenda académica actual: los nuevos formatos destituyentes o "tecnologías del derrocamiento" (RAMíREZ, 2002) mediante las cuales se han implementado golpes de Estado a presidentes legítimos, emanados de la voluntad soberana en órdenes formalmente democráticos, que colocamos en la temporalidad que da inicio al ciclo político del siglo XXI.

Específicamente buscamos, desde la perspectiva de la sociología histórica, comparar tres experiencias: Haití (2004), Honduras (2009) y Paraguay (2012) indagando en los actores - nacionales e internacionales - y en las nuevas formas destituyentes, sin desmerecer el rol de las Fuerzas Armadas, de las clase dominantes y sus partidos tradicionales, tanto como el peso de los bloques regionales e inclusive la injerencia directa que sigue manteniendo Estados Unidos en los países estudiados.

Queremos así discutir con hegemonía discursiva lograda por los actores que emprendieron este nuevo tipo de golpismo. Es decir, como en los diferentes campos discursivos - intelectuales, periodísticos, etc. - se realizó un desplazamiento semántico a la hora de nombrar los golpes de estado, como si el quiebre de la voluntad popular y la soberanía política fueran más "blandos" o más "suaves" porque ya no son tan evidentes y necesarias las armas de los militares ni la violencia física directa como metodología principal de los sectores dominantes para mantener el status quo.

Para realizar el ejercicio nos servimos, anquen no siempre explicitamos, de los intentos de golpes de Estado no logrados tanto como de aquellos golpes de Estado de las Fuerzas Armadas perpetrados durante las décadas de 1960 y 1970 en América Latina, en la búsqueda de una conceptualización.

Asumimos que muchas de las viejas categorías o concepciones no logran captar qué hay de nuevo en los golpismos del siglo XXI y la variedad de "categorizaciones orillan el absurdo: golpe de Estado, sustitución constitucional, golpe parlamentario (con o sin guantes blancos), quiebre institucional, uso de atribuciones legales del Congreso, juicio exprés, mecanismo normal y legal, quiebre o ruptura democrática" (RIVAROLA, 2012, p. 43).

\section{PRECISIONES CONCEPTUALES: ¿RUPTURAS? ¿CAMBIO? ¿GOLPE?}

En su acepción original, presentada por primera vez 1639 por Gabriel Naudé en su obra Considérations politiques sur les coups d'État, el golpe de Estado es un acto llevado adelante por el soberano para desplazar algunos de sus propios funcionarios, acusados de conspirar contra él y así reforzar su propio. En cualquier caso el factor sorpresa y el 
secreto en la gestación eran claves para lograr su cometido. En el siglo XIX el constitucionalismo limitó su expresión a los cambios de gobiernos violando la constitución legal del Estado por parte de los mismos detentores del poder político.

Es decir, que más allá de la temporalidad y especificidad histórica los golpes de estado, ahora se llevan a acabo a través de funcionarios del mismo Estado (el soberano, el titular del poder político legal, los funcionarios civiles o militares) y usando los elementos/las instituciones que formar parte del aparato del Estado, con el objetivo de cambiar al soberano.

En un exhaustivo trabajo, Rafael Martínez (2014) recorre a todos los autores de los siglos XX y XXI que se han ocupado de problematizar y conceptualizar el fenómeno golpista, concluyendo que la diferencia con la definición original de Gabriel Naudé reviste en que mientras en el pasado un golpe de Estado es un instrumento extraordinario de poder absolutista con el que mantener el dominio del príncipe frente a las amenazas externas e internas del Estado, el moderno golpe de Estado no es un acto de defensa o protección del sistema, es un acto que termina con la democracia. Es decir, "frente al golpe de Estado como protección del poder (absolutista) surge el golpe de Estado como ataque al poder (democrático)" (MARTÍNEZ, 2014, p. 203) ${ }^{(1)}$.

Conviene recordar en esta instancia que no siempre un golpe de Estado deriva en una dictadura. Y no siempre esa dictadura es igual en todos los tiempos y lugares. Es decir, no siempre un golpe de Estado instaurar un orden autoritario o militar ${ }^{(2)}$. Originalmente para los romanos, la dictadura era un momento de excepción, necesario para garantizar el orden. Se ponía en suspenso el Estado, para retomar el orden, pero no tenía intenciones de perdurar en él.

No obstante, para la teoría jurídica, el golpe de Estado, en tanto violación de la legalidad del orden anterior implica también el cambio de su norma fundamental y por lo tanto la validación de todas sus leyes (más allá de introducir o no cambios). De ahí que, para el derecho internacional un gobierno surgido de un golpe de Estado deba pedir/ recibir reconocimiento de los demás Estados.

Con excepción del trabajo recientemente citado, las producciones actuales sobre la temática que nos ocupa se encuentran mayormente en los periódicos y de forma fragmentaria en algún suplemento especializado en América Latina. La sociología ha hecho caso omiso, al igual que la historia, y tanto la ciencias del derecho como la politología

(1) Rafael Martínez (2014) propone siete propiedades variables que se van conjugando con la definición núcleo de golpe de Estado (constante), que arrojan ocho subtipos teóricos posibles de golpes de estado "más allá de si hay ejemplos que respondan a cada uno de los modelos" (XX). Lo que le interesan al autor es marcar las diferencias que presentar los golpes de "nueva generación", es decir desde 1970 a la actualidad. Nosotros intentamos otro camino, caracterizar actores, mecanismo y contexto sociohistóricos, específicamente el internacional, que nos acerque a un problema común y su caracterización para un concepto mínimo de golpe de Estado del siglo XXI.

(2) Otra larga discusión en las ciencias sociales es si un golpe de Estado puede devenir en una revolución. Apelando a Theda Sckocpol (1984), se puede afirmar que los golpes, a diferencia de los procesos revolucionarios han impedido la movilización de masas o las revueltas desde abajo. Pero, hay excepciones, como lo son para la la autora el golpe que derribo a la dictadura de Salazar en Portugal y la Revolución de etíope que se inició con un golpe de Estado, donde oficiales rebeldes se volvieron hacia la movilización de masas contra la aristocracia terrateniente. 
han intentado reflotar algunas de sus viejas categorías: "inestabilidad presidencial" (OLLIER, 2008), "caídas presidenciales" (HOCHSTETLER, 2008), "remoción del presidente" (PÉREZ LIÑÁN, 2007) o "presidencias interrumpidas", "interrupciones institucionales" (NEGRETTO, 2006).

Sin embargo, todas estas categorías no dan cuenta del proceso que actualmente está en marcha y resultan a históricas para lo que aquí se intenta analizar. En efecto, fueron pensadas en el marco de las crisis políticas postransición a la democracia en 1980 y, específicamente, para los mandatos no finalizados de los presidentes del período neoliberal en la región.

Como ha indicado Pérez-Liñán (2009), "estirar" la etiqueta de golpe de Estado lleva a "un callejón sin salida", porque podría derivar en que toda caída de un presidente pueda ser denunciada ante la OEA bajo tal denominación y, según mayorías circunstanciales, convertirse en un recurso de "intervención arbitraria". Para dicho autor, el nuevo patrón de inestabilidad política se caracteriza por el surgimiento de crisis recurrentes que conducen a la remoción o renuncia de presidentes, sin que ello implique la ruptura democrática.

Sin embargo, en este texto no buscamos explicar los golpes de Estado como un problema de instabilidad política, muchas veces inculpada a los presidencialismos en América Latina. Por el contrario, la inestabilidad puede ser un elemento decisivo en la apertura de un proceso de cambio social, como se muestra actualmente en la región. Los golpes de Estado contra Jean Bertrand Aristide en Haití (2004), Manuel Zelaya en Honduras (2009) y Fernando Lugo en Paraguay (2012), así como los intentos de golpes no logrados - contra Hugo Chávez Frías en Venezuela (2002), Evo Morales en Bolivia (2008) y Rafael Correa en Ecuador (2010) -, plantean algunas diferencias sustanciales con la caída de los presidentes de los años 1990, producidos en el contexto de crisis del neoliberalismo como matriz dominante de acumulación y de dominación.

Entre los años 2000 y 2005 hubo al menos seis presidentes en ejercicio que no pudieron culminar su gobierno por causa de las grandes movilizaciones sociales: Jamil Mahuad (2000) y Lucio Gutiérrez (2005) en Ecuador, Alberto Fujimori (2000) en Perú, Fernando de la Rúa (2001) en Argentina; Gonzalo Sánchez de Lozada (2003) y Carlos Mesa (2005) en Bolivia. Sin embargo, estas destituciones implicaron movimientos populares, movilizaciones y lógicas de insurrección callejeras, que produjeron la caída de los gobiernos que venían gestionando un modelo neoliberal.

Todas estas destituciones estuvieron siempre acompañadas de movilizaciones ciudadanas de descontento. Y asimismo, procedidas por gobiernos reformistas. No es el caso de las experiencias que inauguran los golpismos del siglo XXI, pues la restauración que se busca es de derecha. Nueva derecha para algunos autores, menos nueva para otros, quienes se pregunta si en rigor no hay un retorno a los orígenes de la democracia burguesa (ANSALDI, 2014, p. 26).

Por todo esto, a diferencia de aquellos procesos de inestabilidad presidencial de los años 1980-1990, los golpes de estado del siglo XXI siempre intentan anular, eliminar o inhibir (de acuerdo a la correlación de fuerzas encontrada y la capacidad para imponer 
una nueva voluntad política) un proceso en marcha que en general aparece como una amenazada al orden estatuido y afecta los interés de los sectores económicos y políticos concentrados.

Algo que Perry Anderson denominó contrarrevoluciones preventivas, en respuesta a la "inflexión populista" de los años 1950. Como indica Ansaldi (2014, p. 28) "cuando se produce una radicalización de la democracia que llegara al punto de cuestionar seriamente la hegemonía de la burguesía, esta clase no vacilará en el empleo de la violencia, cualquiera sea la forma que elija". Se trata, en este caso, de acciones destinadas a sustituir los productores del orden social, modificando la dirección de los procesos constituyentes nacidos de la crisis neoliberal.

\section{LOS ACTORES Y MODALIDADES INTERVINIENTES EN LOS GOLPES DE ESTADO EN EL SIGLO XXI}

Según Juan Gabriel Tokatlian (2009; 2012) el neogolpimo es una modalidad formalmente menos virulenta, encabezado por civiles (con soporte implícito o complicidad explicita de los militares) que pretende violar la constitución del Estado pero preservando cierta apariencia o semblanza institucional mínima (por ejemplo, con el Congreso en funcionamiento y/o la Corte Suprema temporalmente intacta). Los golpes no siempre involucran a una gran potencia (por ejemplo, Estados Unidos) y pretenden resolver una encrucijada social y política crítica más que a fundar un orden novedoso.

Es un fenómeno gradual, donde los grupos civiles van generando condiciones o escenarios para la inestabilidad y se tiende a invocar - y agregamos nosotros, a utilizar - la opción de una salida constitucional, legal, institucional. Es decir, el nuevo golpismo reconoce que los gobiernos fueron elegidos democráticamente, pero argumenta que ellos no gobiernan democráticamente. Es justamente en esa ambigüedad que caracteriza a los golpes de Estado del siglo XXI, donde es posible dotar de una continuidad institucional, para disimular prácticas antidemocráticas.

De hecho, el argumento político utilizado es que su intervención se produce para resguardar un orden democrático, apelación que utilizaron también las Dictaduras Institucionales de las Fuerzas Armadas en el Cono Sur. Sin embargo, hoy es más frecuente es que todos los golpistas centren sus esfuerzos ya no en legitimar a posteriori su acción - que reconocían ilegal -, sino en demostrar la legalidad de todos y cada uno de los actos que han llevado a término para suplantar al poder ejecutivo.

De ahí que algunos autores pretendan denominar las nuevas modalidades golpistas como de Golpes de Estado constitucionales (ROITMAN, 2013) ya que éstos se caracterizan por hacer uso de mecanismos constitucionales para cubrir las irrupciones al poder con un manto de legalidad, y con la participación de autoridades elegidas democráticamente. En este sentido, puede afirmarse que:

La visión tradicional de los golpes de Estado en América Latina ha pasado a mejor vida, pero siguen en la agenda de las clases dominantes latinoamericanas, que nunca han desaparecido (...) Las Fuerzas Armadas no requieren al menos por el momento, implantar el 
terror. Los golpes exclusivamente militares, perpetrados por la gran autonomía concedida a las Fuerzas armadas en tiempos de Guerra Fría desaparecen, ceden su lugar a los golpes constitucionales, más limpios y efectivos (ROITMAN ROSENMANN, 2013, p. 200).

La autonomía que las Fuerzas Armadas poseyeron durante la Guerra Fría, fue recortada por las autoridades civiles y en los casos que actuaron fue a partir de una petición de los poderes legislativo y judicial.

A diferencia de los golpes tradicionales en América Latina gestados desde las Fuerzas Armadas para quedarse con el poder, en el caso de Honduras, Paraguay y Haití las Fuerzas Armadas no actuaron por propia iniciativa, no utilizaron la violencia física ni intentaron "asaltar" el gobierno, dado que no contaban con el poder ni la autoridad para hacerlo (LLANOS Y LEIV, 2010). Sin embargo, a diferencia de Paraguay, en Honduras y Haití las Fuerzas Armadas sí tuvieron participación.

El golpe de Estado contra Jean-Bertrand Aristide (2004) tuvo injerencia, no sólo de la policía que el propio presidente había creado sino también de las Fuerzas Armadas que continúan siendo una fuerza de choque directa de los Estados Unidos en ese país.

Pero también sucedió en Honduras, cuando el presidente Zelaya destituyó al general Romeo Vásquez como jefe del Estado Mayor Conjunto de las Fuerzas Armadas por negarse a distribuir los materiales electorales para la consulta popular que abriría el camino a la reforma constitucional, o como cuando deportaron a Zelaya a Costa Rica en un avión militar. Más aún: el principal asesor legal de los militares admitió que "la decisión de sacarlo a Costa Rica la tomamos nosotros como Fuerza Armada” (MANAUT y DIAMINT; 2010, p. 150).

Además, el avión argentino en el que viajaban Manuel Zelaya, la presidenta Cristina Fernández de Kirchner y el presidente Rafael Correa fue impedido de llegar a destino por el despliegue de transportes militares en la pista de aterrizaje.

Este punto requiere, entonces, volver a ubicar a las Fuerzas Armadas en función del lugar que tuvieron y tienen en la construcción del orden y en el bloque de dominación, tanto como observar el papel predominante que tuvieron en los partidos políticos tradicionales y las clases políticas ligada a ellos, principales ejecutores de los procesos destituyentes.

Basta observar cómo los parlamentos funcionan como refugios institucionales para la reorganización política de las diferentes oposiciones de las élites. Así, la "ideología parlamentarista" es un fenómeno construido con el esfuerzo combinado de las élites conservadoras de cada país en alianza con los medios de comunicación, "que fuerzan una específica interpretación de la realidad en la que se desvaloriza la legitimidad de los poderes ejecutivos" (SALAS OROÑO, 2010).

En los golpes de estado del siglo XXI la violencia reaccionaria y física juega sólo un papel auxiliar, comparada con la de los medios de comunicación generadores de la narrativa de la crisis o del consenso. En todos los casos los medios de comunicación junto con las redes sociales de comunicación instantánea han sido centrales en la creación de una ideología golpista, a través de núcleos argumentativos comunes para justificar las 
intervenciones. Se construye así la representación del gobierno 'aislado' - pese a contar con un apoyo popular mayoritario - y de la necesidad de poner fin a la conflictividad y el enfrentamiento entre "ciudadanos de la misma nacionalidad".

El conflicto social no se vincula a la disputa de intereses económicos o al enfrentamiento de clases - claramente puesto de manifiesto en Bolivia y Venezuela - sino a la "incapacidad" de los mandatarios para gobernar, así como a las desmedidas ambiciones de los movimientos sociales. Paradójicamente, al tiempo que se califica a los gobiernos como presidencialistas con una "tendencia autoritaria" que busca perpetuarse en el ejecutivo, se manifiesta un "vacío de poder" y un clima de ingobernabilidad política que atraviesan las instituciones de estos países.

Esta narrativa ha logrado constituirse en sentido común en sectores importantes de la población - especialmente sectores medios-altos relacionados con la formación de opinión pública - y la destitución "aparece" como la "confirmación" del proceso de erosión de la legitimidad presidencial previamente producido y "permitido" a raíz de este último acontecimiento (GOLDSTEIN; 2012, p. 02).

Al momento del golpe de Estado en Paraguay los medios de comunicación eran la institución, junto a la Iglesia, mejor valorada (5,79 de 10) (DE ANCOS; JUSTE, 2014, p. 19). Se conoce además a Gene Sharp (1988) quien ha desarrollado a pedido de la CIA un manual de criterios y metodologías acerca de cómo implementar el terror y la conmoción mediantes métodos no convencionales, es decir, no violentos.

Sin embargo, los métodos de la remoción autoritaria no han sido idénticos. En Paraguay fue posible televisar un juicio exprés (ver "Apéndice 01"), en el cual no se presentó una sola prueba porque las mismas, según el líbelo acusatorio, eran "de público conocimiento". En dicha apelación se recurrió a la cláusula madre de la represión dictatorial: los delitos políticos no necesitan ser probados por ser "de público conocimiento".

Esa acusación, radicalmente opuesta al contrato republicano y democrático de 1992, fue públicamente aprobada por la casi totalidad de la Cámara, que sancionó así el retorno al contrato dictatorial.

Diferentes fue el caso de Honduras, que aun habiendo utilizado "argumentos legales" con preeminencia del parlamento (ver "Apéndice 02)", se debió apelar al secuestro y expulsión de Zelaya, quien fue retirado de madrugada vía intervención militar. En cambio, en Haití es posible otorgarle, como veremos, un mayor peso explicativo al rol estratégico desempeñado principalmente por los Estados Unidos.

\section{LA DIMENSIÓN INTERNACIONAL DEL GOLPISMO}

A diferencia de los golpes de Estado de los años 1970 que se producían en el marco de la intensa disputa bipolar, los golpes de estado del siglo XXI se producen en un escenario pos 11 de septiembre donde política exterior comienza a estar amparada en paradigma del terrorismo. 
No obstante, es relevante considerar la dimensión internacional del neogolpismo y, especialmente, el rol de las instituciones regionales como Unasur y Mercosur, las cuales se mostraron impotentes para devolver a los presidentes depuestos a sus cargos, aunque impusieron suspensiones a Honduras y Paraguay hasta que un nuevo proceso electoral decidiera por nuevos presidentes y autoridades políticas.

Para ello se apeló al protocolo sobre compromiso democrático del Mercosur, conocido como "Ushuaia II" y al "Protocolo Adicional al Tratado Constitutivo de la Unasur sobre Compromiso con la Democracia", suscrito en Guyana el 26 de noviembre de 2010, luego del intento destituyente al presidente ecuatoriano Rafael Correa en el año 2010, entrando en vigor el 19 de marzo de 2014. Ambas clausulas tienen un gran valor punitivo y son creadas una vez quebrado el orden constitucional en uno de sus países miembros.

Es importante remarcar que Brasil adoptó un pulso político diferente. Mientras encabezó la protesta latinoamericana en la OEA y le abrió las puertas de su embajada a Manuel Zelaya, fue el más cauto de todos los países de la región a la hora de condenar el Golpe en Paraguay. En efecto, ello responde a los diferentes intereses comerciales y económicos que posee, puesto que comparte con Paraguay la represa de Itaipú y una amplia frontera sojera.

En el caso de Honduras, el repudio provino principalmente de la diplomacia multilateral, encabezada por el presidente de Costa Rica, Oscar Arias, quien diseñó el "Plan Arias" para lograr la restauración de Zelaya. La Unión Europea, el Banco Interamericano de Desarrollo (BID) y el Fondo Monetario Internacional (FMI) anunciaron el cese de la asistencia financiera y Estados Unidos deportó a Honduras a Bianca Micheletti, hija del presidente de facto, que trabajaba en la embajada hondureña en Washington.

Este proceso ha implicado un cambio respecto a 2002 cuando se produjo la fracasada remoción de Hugo Chávez en Venezuela, ya que en esta oportunidad Estados Unidos no condenó el golpe; más aún lo justificó como lo hicieron otros países como España y Colombia. Dos años más tarde, en 2004, se produjo la salida forzada de Jean-Bertrand Aristide en Haití, y en donde los mecanismos y los argumentos se repitieron: "la crisis institucional lo llevó a su propia remoción".

Sin embargo, a diferencia de Venezuela en vez de detener temporalmente a Aristide, el embajador de Estados Unidos puso al depuesto mandatario haitiano en un avión y lo envío a la República Centroafricana y el golpista François Bozizé hizo redactar una nueva Constitución, que le permitió ser electo presidente en 2003.

Los casos de Honduras y de Haití contienen un aditivo particular para repensar el mapa imperialista norteamericano en la destitución de ambos presidentes. El presidente de Jean-Bertrand Aristide es un buen ejemplo de la interferencia del gobierno estadounidense en los asuntos internos haitianos, en tanto fue dos veces depuesto con la intervención directa de los Estados Unidos.

En 1991, luego de seis meses de asumir y dar inicio a un proceso de transición a la democracia, fue derrocado por un grupo de militares encabezado por el general Raoul Cédras, logrando su exilio en Venezuela y luego en Estados Unidos. La dictadura establecida por el Raoul Cédras le valió la condena internacional y sanciones económicas de 
Europa y específicamente de Francia, razón por la cual Aristide volvió a Haití en octubre de 1994 - tres años después del golpe de Estado -, acompañado de una tropa multinacional encabezada por Estados Unidos.

Allí culminó su período presidencial. En el año 2000 Aristide volvió a ganar las elecciones con un triunfo abrumador, cristalizando así una legitimidad que lo condujo a intentar implementar algunas reformas, restableciendo relaciones diplomáticas con el gobierno de Cuba y Venezuela. Su gobierno duró ahora seis meses en los cuales el papel de Estados Unidos fue central, ante la posibilidad de modificar las relaciones multilaterales en Centroamérica.

La República de Sudáfrica exigió a las Naciones Unidas la conformación de una comisión de investigación internacional sobre el caso de Haití. La instancia nunca se creó y a los dos meses del golpe de Estado, se envió a Haití una Misión de Estabilización de las Naciones Unidas (Minustah). Después del terremoto que devastó a la isla en enero de 2010, la Minustah se replegó ante la presencia de más de 20.000 marines estadounidenses en territorio haitiano.

Manuel Zelaza, en acuerdo con Hugo Chávez y como parte de la estrategia geopolítica venezolana en América Central, había firmado el tratado para incorporase al ALBA - Alianza Bolivariana para los pueblos de nuestra América - aun cuando Honduras ya contaba con tratados de libre comercio con Estados Unidos y otros países que integran el DR-CAFTA (Tratado de Libre Comercio entre República Dominicana, Centroamérica y Estados Unidos de América). Sin embargo, cinco meses después del golpe de Estado se inició el procedimiento para retirarse definitivamente del ALBA, concluyendo el 12 de enero de 2010 cuando el Congreso Nacional de Honduras - con 123 votos a favor y 5 en contra - aprobó la renuncia al tratado. En el mismo acto, Venezuela suspendió a Honduras del programa de Petrocaribe.

Asimismo, los tres países que estamos estudiando cuentan con bases militares norteamericanas. Bien es conocida la injerencia de Estados Unidos en Honduras, como parte de la política exterior desarrollada sobre Centroamérica y específicamente en su ofensiva contra el sandinismo.

Según la investigación de Telma Luzzani (2012, p. 408) en la base militar Soto Cano $^{(3)}$ opera la Fuerza de Tarea Conjunta Bravo del Comando Sur, que en los años 1980 fue clave en la guerra antisandinista y otros movimientos. Es la pista más extensa de Centroamérica y el Pentágono está en condiciones de coordinar toda su presencia militar en Centroamérica desde ahí, incluido el movimiento de la ADEA en territorio guatemalteco.

En Paraguay, la dependencia imperialista ha sido más solapada, pero no por ello menos importante. Como lo revelan los recientes cables de Wikileaks, Fernando Lugo había autorizado la injerencia de Estados Unidos para el entrenamiento de fuerzas especiales denominadas Destacamento conjunto de Respuesta Rápida con miras a derribar

(3) 28 días antes del golpe, Manuel Zelaya había anunciado que la base de Soto Cano se utilizaría en el futuro para vuelos comerciales y que la construcción de la terminal civil iba a ser financiada por el ALBA. 
la supuesta guerrilla del EPP (Ejército del Pueblo Paraguayo) que todavía no se sabe si existe como tal, qué características tiene o quiénes la componen. Los datos aportados por la misma inteligencia norteamericana revelan que tienen "más de banda delictiva que de vanguardia revolucionaria".

Todos estos factores han propiciado el clima para que el reciente presidente, el empresario colorado Horacio Cartes, envíe una ley al Congreso para que las Fuerzas Armadas se involucren en tareas antisubversivas. La ley Antiterrorista, como se la conoce, aprobada en ambas cámaras, contó con el voto del ex presidente Lugo, electo senador en abril de 2013.

\section{DEMOCRACIA Y GOLPISMO. ELEMENTOS PARA UN CONCEPTO MÍNIMO DE GOLPES DE ESTADO EN EL SIGLO XXI}

Edelberto Torres Rivas (2010) ha sostenido con refinada ironía que el golpe en Honduras ha demostrado cuán irreversible es la democracia. Frase que hago propia para pensar Paraguay y Haití. En todos los casos, millones de ciudadanos han participado en aproximadamente 20 y 30 elecciones nunca impugnadas por fraude. Dichas elecciones se han realizado bajo la egida de Estado que sigue acobijando las mayores precariedades.

O peor aún, democracias que desde los años 1980 generan sociedades más desiguales y pobres. No es casual que los golpes se hayan perpetrado en países donde se observan indicios de erosión de la legitimidad democrática con los más altos grados de desigualdad, pobreza, exclusión y violencia sociales de la región, siendo Haití el principal exponente.

Pero también Paraguay y Honduras exhiben tasas alarmantes, respecto sobre todo al acceso a la tierra: en Honduras, hasta un 30 por ciento del territorio nacional pertenece a transnacionales, mientras que en Paraguay un 2,5 por ciento de la población posee sólo un 85 por ciento de las tierras. En tales contextos, la emergencia del golpismo se produce, en palabras de Emir Sader (2012), sobre los "eslabones más débiles".

En Honduras, pero también en Paraguay y en Haití, no se trató de una democracia surgida "desde abajo" sino a partir de una estrategia clara de los Estados Unidos y un acuerdo de élites. En Honduras, el pacto entre el Partido Nacional (ligado históricamente a Cuyamel Fruit Co) y del Partido Liberal (ligado históricamente a la United Fruit Co), garantizó la estabilidad institucional de la democracia durante años junto con un destacado inmovilismo social.

Lo mismo debe afirmarse para Paraguay, donde Colorados y Liberales acordaron un pacto con la elite golpista y stronista que asegurase la transición. Por ello, en el momento de perpetrarse el golpe, Federico Franco era el vicepresidente de Fernando Lugo en la fórmula presidencial y Roberto Micheletti, el primero en la línea presidencial del gobierno de Manuel Zelaya. En todos los casos, el actor central fue la clase política vinculada a los partidos tradicionales que contaron con el apoyo explícito en Haití y Honduras de las Fuerzas Armadas y con una derecha trasnacionalizada pero con clara injerencia local, cada vez más tentada por volver al Estado (no ya sólo al gobierno). 
Los golpes de estado del siglo XXI quiebran un proceso de radicalización democrática o su posible amenaza mediante actores civiles - pero no siempre con neutralidad militar ni externa - que tienen como prioridad justificar la legalidad y legitimidad de lo ocurrido. "(...) del Golpe como acto de ilegalidad necesaria y legítima, hemos llegado al golpe de Estado "con todas las de la ley” (MARTÍNEZ, 2014, p. 204).

Con nuevos formatos dotados para dar continuidad constitucional al proceso golpista y no presentar quiebres democráticos - como ocurrió con la excepción autoritaria de los golpes de estado del contexto de la Guerra Fría - los golpismos del siglo XXI intenta frenar o eliminar un proceso de cambio en el que los sectores dominantes, al verse afectados, despliegan su capacidad de imponer sus intereses y derribar el gobierno vigente.

Ningún golpe de Estado es exitoso si no logra apoyos de la burguesía nacional y/o trasnacional y cuenta con desmovilización social garantizada, que luego la ruptura del pacto democrático no hace más que reafirmar. En rigor, los golpes de estado en Honduras, Haití y Paraguay no contaron con un movimiento popular ni con movilizaciones políticas con capacidad de interponerse, tal como ocurrió en otras intentonas en Bolivia, Venezuela y Ecuador. Donde el golpismo logro su objetivo que la ciudadanía vivió como espectadora un juego de elites, porque tampoco se sintió interpelada por una pobre democracia.

\section{BIBLIOGRAFÍA}

ANSALDI, Waldo. De la vox populi, vox deus, a la vox populi, vox mercatus. La cuestión de la democracia y la democracia en cuestión. Estudios, Córdoba, n. 31, p. 13-33, 2014.

DE ANCOS, Juste Rubén. Hegemonía colorada y alternancia política en Paraguay: Los límites de la victoria de Horacio Cartes. Revista Novapolis, n. 7, p. 11-35, 2014.

GOLDSTEIN, Ariel. Una aproximada periodización de los procesos destituyentes. Rebelión 16.07.2012. Disponible en: <http://www.rebelion.org/noticia.php?id=153079>.

HOCHSTETLER, Kathryn. Repensando el presidencialismo: desafíos y caídas presidenciales en el Cono Sur. América Latina Hoy, Salamanca, n. 49, p. 51-72, 2008.

LLANOS, Mariana; MARSTEINTREDET, Leiv. Ruptura y continuidad: la caída de "mel" Zelaya en perspectiva comparada. América Latina Hoy, n. 55, p. 173-197, 2010.

LUZZANI, Telma. Territorios vigilados. Como opera la red de bases militares norteamericanas en Sudamérica. Buenos Aires: Debate, 2012.

MANAUT, Raúl Benítez; DIAMINT, Rut. La cuestión militar. El golpe de Estado en Honduras como desafío a la democracia y al sistema interamericano. Nueva Sociedad, n. 226, p. 146-157, 2010.

MARTÍNEZ, Rafael. Subtipos de golpe de Estado: trasformaciones recientes de un concepto del siglo XVII. Revista CIDOB d'Afers Internacionals, n. 108, p. 191-212, 2014.

NEGRETTO, Gabriel. Minority Presidents and Democratic Performance in Latin America. Latin American Politics and Society, n. 48, p. 63-92, 2006.

OLLIER, María Matilde. La institucionalización democrática en el callejón: la inestabilidad presidencial en Argentina (1999-2003). América Latina Hoy, Salamanca, n. 49, p. 51-72, 2008.

RAMÍREZ, Franklin. ¿Hegemonías emergentes? Golpismo, política y resignificación democrática. Un contrapunto ecuatoriano-venezolano. Las FF.AA en la región andina: ¿actores deliberantes o subordinados? Perú: Comisión Andina de Juristas/Embajada de Finlandia, 2002. 
RIVAROLA, Milda. La rescisión del contrato social. In: CARBONE; Rocco y SOLER, Lorena (eds.). Franquismo en Paraguay. El Golpe, Buenos Aires: El 8vo loco Ediciones, 2012.

ROITMAN Rosenmann, Marcos. Tiempos de oscuridad. Historia de los golpes de Estado en América Latina. Madrid: Akal, 2013.

SADER, Emir. Paraguay, el eslabón más débil. CARBONE, Rocco y SOLER, Lorena (eds.). Franquismo en Paraguay. El Golpe, Buenos Aires: El 8vo loco Ediciones, p. 131-133. 2012.

SALAS OROÑO, Amilcar. La "parlamentarización" de la política en América Latina. Centro de Estudios Políticos y Sociales, Valencia, 2010.

SHARP, Gene. La lucha política no violenta. Criterios y métodos. Santiago: Ediciones Chile América, 1988.

SKOCPOL, Theda. La explicación de las revoluciones sociales: otras teorías. Los Estados y las revoluciones sociales. Ciudad de México: Fondo de Cultura Economía, 1984

TOKATLIAN, Juan Gabriel. "Neogolpismo". Página/12, 13 de julio de 2009. Disponible en: <http:// www.pagina12.com.ar/diario/elmundo/subnotas/128159-41146-2009-07-13.html>.

TOKATLIAN, Juan Gabriel. "El auge del neogolpismo", La Nación, 24 de junio de 2012. Disponible en: <http://www.lanacion.com.ar/1484794-el-auge-del-neogolpismo>.

TORRES RIVAS, Edelberto. Las democracias malas de Centroamérica. Para entender lo de Honduras, una introducción a Centroamérica. Nueva Sociedad, n. 226, p. 52-66, 2010.

\section{APÉNDICE 1}

La Cámara baja (con el voto de 115 diputados de un total de 125) acusó al Presidente de cinco hechos que se detallan en el libelo acusatorio:

I. haber utilizado las instalaciones del Comando de Ingeniería de las Fuerzas Armadas en 2009 para un acto considerado "político-partidario" que se denominó Campamento Latinoamericano de Jóvenes por el Cambio.

II. ser "instigador" y "facilitador" de las tomas de tierras en la zona de Ñacundaí y el uso de las fuerzas militares "para generar un verdadero estado de pánico" en la región.

III. haber demostrado ser incapaz para desarrollar políticas y programas que busquen disminuir la "inseguridad ciudadana".

IV. haber apoyado el protocolo regional sobre el compromiso con la democracia en el Mercosur (Ushuaia II) que sería interpretado como una violación de soberanía. Según dicho pacto, se indicaba que se penaría con la exclusión a cualquier país donde tuviera lugar un golpe de Estado. Para los diputados, este documento podría derivar en el corte del suministro de energía a Paraguay.

V. "falta de reacción" frente a la muerte de 17 personas en Curuguaty.

\section{APÉNDICE 2}

El 8 de mayo, el Procurador General de la Nación, actuando como garante de la Constitución, solicitó a la Corte Suprema que declarara la ilegalidad y nulidad de la decisión del Poder Ejecutivo de llamar a una consulta popular para habilitar la reelección 
no inmediata del presidente. La consulta fue declarada ilegal por la Fiscalía, el Congreso y el Tribunal Supremo Electoral. La Corte Suprema ordenó a Zelaya que restituyera a Vásquez en su cargo, ahondando el enfrentamiento entre los poderes del Estado. La justificación legal del golpe se basó en la inconstitucionalidad de la consulta. El decreto n. 141-2009 del 28 de junio de 2009 acordaba separar al ciudadano José Manuel Zelaya Rosales del cargo de Presidente Constitucional de la República de Honduras por las reiteradas violaciones a la Constitución. Los artículos 304 y 306 de la Constitución permiten llamar a la fuerza pública para hacer cumplir con los mandatos de la Corte (BENÍTEZ MANAUT y DIAMINT, 2010). 